\title{
In Sickness and in Health: The Oxygen Reactive Species and the Bone
}

\author{
Joana Reis ${ }^{1 *}$ and António Ramos ${ }^{2}$ \\ ${ }^{1}$ Agronomic and Veterinary Sciences, School of Agriculture, Polytechnic Institute of Viana Do Castelo, Ponte de Lima, Portugal, \\ ${ }^{2}$ TEMA, Mechanical Engineering Department, University of Aveiro, Aveiro, Portugal
}

Oxidative stress plays a central role in physiological and pathological bone conditions. Its role in signalment and control of bone cell population differentiation, activity, and fate is increasingly recognized. The possibilities of its use and manipulation with therapeutic goals are virtually unending. However, how redox balance interplays with the response to mechanical stimuli is yet to be fully understood. The present work summarizes current knowledge on these aspects, in an integrative and broad introductory perspective.

Keywords: oxidative stress, bone, mechanobiology, redox balance, mechanotransduction

\section{INTRODUCTION}

\section{OPEN ACCESS}

Edited by:

Dario Loureiro Santos,

Universidade de Trás-os-Montes e

Alto Douro, Portugal

Reviewed by:

Aurélie Carlier,

Maastricht University, Netherlands

Uriel Zapata

EAFIT University, Colombia

*Correspondence:

Joana Reis

jmargaridareis@esa.ipvc.pt

Specialty section:

This article was submitted to Biomechanics,

a section of the journal Frontiers in Bioengineering and Biotechnology

Received: 22 July 2021 Accepted: 28 October 2021 Published: 23 November 2021

Citation:

Reis J and Ramos A (2021) In Sickness and in Health: The Oxygen Reactive

Species and the Bone.

Front. Bioeng. Biotechnol. 9:745911. doi: 10.3389/fbioe.2021.745911
Oxidative stress plays an important role in homeostasis and disease in most tissues. Reactive species are continuously generated as byproducts of normal cellular metabolism. Antioxidant mechanisms, acting via specific scavenger reactions and detoxification pathways, revert its accumulation and avoid oxidative stress-related damage (Reis et al., 2021). Curiously, for some processes, the existence of a transitory oxidative stress is a biological necessity. However, when oxidative stress remains because of an imbalance between the production and scavenging of reactive species, it results in an array of physiopathologic changes, consequence of a spiral of new sources of free radicals and oxidative species and increased damage (Reis et al., 2021).

In the literature, the term reactive oxygen species (ROS) is often used to encompass all reactive species, regardless of the specific chemical species. Other authors differentiate reactive nitric species (RNS) when referring to nitric oxide and nitrogen dioxide free radicals, peroxynitrite, and nitrite/nitrate (Sies et al., 2017). ROS are mainly produced by mitochondria, the foundational organelle for energy generation in cells, intervening in many of the cell signaling cascades (McBride et al., 2006; Quirós et al., 2016; Zheng et al., 2020). The most important oxygen free radicals include hydrogen peroxide $\left(\mathrm{H}_{2} \mathrm{O}_{2}\right)$, hydroxyl radical $(-\mathrm{OH})$, superoxide anion radical $\left(\cdot \mathrm{O}_{2}-\right)$ and nitric oxide (NO). However, other oxygen-derived free radicals have relevant roles in cell metabolism, such as the peroxyl radical cation and other hydroperoxides (Dröge, 2002).

Oxidative stress is being increasingly recognized by its dual role, no longer the cause and root of all evil. ROS generation is not only essential as part of the immune cells' response against pathogens but may act to signal and modulate cell responses, essential for life. Oxidation-reduction (redox) homeostasis is ubiquitous to living cells, tissues, organs, systems. Oxidative eustress or physiological oxidative stress is positive and a fundamental signal and control mechanism (Sies et al., 2017); low concentrations of ROS and RNS allow reversible oxidative/nitrosative modifications of redoxsensitive residues in regulatory proteins; these modifications may translate into a loss or gain of function or a change of function (Dröge, 2002; Moldogazieva et al., 2018). Oxidative distress is associated with high burden, supraphysiological oxidative challenge and has deleterious consequences, leading to oxidative damage of biomolecules and disruption of the redox signaling pathways (Sies, 2019). 
The skeletal system shares with the cardiovascular, muscular, and connective tissues its embryonic mesodermal origin; thus it is possible these tissues share some regulatory pathways. NO has an essential function in cardiovascular function. The nitric oxide synthase (NOS) in the endothelial cells regulates vascular smooth muscle relaxation through nitric oxide synthesis, mediates angiogenesis, and controls muscle cell proliferation; diffused $\mathrm{NO}$ inhibits platelet aggregation and thrombogenesis (Farah et al., 2018). In blood vessels, NO is released in response to stimuli such as shear stress. It has been hypothesized that the signaling pathways leading to anti-atherogenic or proatherogenic vascular wall reactions are ROS/RNS dependent and depend on the flow patterns (Hsieh et al., 2014); the endothelial cells are sensitive to fluid shear and several processes, including vascular tone and remodeling, angiogenesis and vascular morphogenesis are modeled by these forces and the resulting cell response (Roux et al., 2020).

Bone is highly dynamic, its form and cellular activity continuously tailored by load and strain, responsive to external and internal stimuli. Environment, cell-to-cell, and cell-matrix interactions regulate osteogenesis, bone repair, and remodeling, a process coupling bone resorption and formation. Bone homeostasis is strongly intertwined with intracellular reactive species production, namely reactive oxygen species (ROS) and reactive nitric species (RNS).

This paper intends to condense the current knowledge on the role of the redox balance in physiological and pathological conditions in bone, as well in the presence of orthopedic implants, and establishing connections to bone mechanobiology, still largely unexplored in this aspect. It is aimed at those that, like the authors, come from a clinical or mechanical and biomedical engineering background.

\section{OXIDATIVE STRESS IN BONE HOMEOSTASIS}

Mature bone contains three key cell populations: osteoblasts, osteocytes and osteoclasts. While osteoblasts differentiate from mesenchymal stem cells, and may differentiate into osteocytes, osteoclasts arise from the same lineage as macrophages and monocytes. The bone remodeling process depends on the coordinate action of the different cell populations; osteoblastic bone formation activity must be balanced by osteoclastic resorptive action (Figure 1). Osteoblasts and osteocytes express membrane-bond RANKL (receptor activator of nuclear factor NF- $\kappa \mathrm{B}$ ligand) and this regulatory molecule interacts with a receptor - RANK (receptor activator of nuclear factor- $\kappa \mathrm{B}$ ) -, expressed on the surface of osteoclast precursors. RANK activation by RANKL is essential for fusion of the osteoclast precursor cells and osteoclast formation (da Costa Reis \& Oliveira, 2020; Nakashima et al., 2011). Osteoblasts also secrete osteoprotegerin (OPG), an inhibitor of osteoclastogenesis. The $\mathrm{Wnt} / \beta$-Catenin pathway is fundamental for bone-mass homeostasis; osteocytes are key to the canonical Wnt signaling pathway regulation, for they produce Wnt ligands, are targeted by these and secrete molecules that modulate Wnt actions (Al-Bari \& Al Mamun, 2020).

$\mathrm{NO}$ and prostaglandin E2 (PG E2) are released by osteoblastic lineage cells under cyclic mechanical load; strain applied through the substrate and through fluid flow stimulated the release of nitric oxide (Mullender et al., 2004; Frias et al., 2010; Yavropoulou and Yovos, 2016). Nitric oxide and PG E2 are essential for balanced bone remodeling since both are related to RANKL expression (Huang et al., 2017; I; ntemann et al., 2020). PG2 induces RANKL expression in osteoblasts, in an autocrine and paracrine manner via activation of the EP4 receptor, and exerts regulatory action on angiogenesis and vascular permeability, thus, modulating bone metabolism (Intemann et al., 2020).

Superoxide synthesis by the osteoclasts' NADPH oxidases (Nox) is also necessary to allow bone resorption in physiological bone remodeling processes (Darden et al., 1996). There are three identified Nox isoforms involved in osteoclast differentiation and function, Nox1, Nox2, and Nox4. Nox isoforms expression is controlled by several mechanisms such as the transcription factor nuclear factor-erythroid 2-related factor (Nrf2), key to antioxidant cellular responses, and

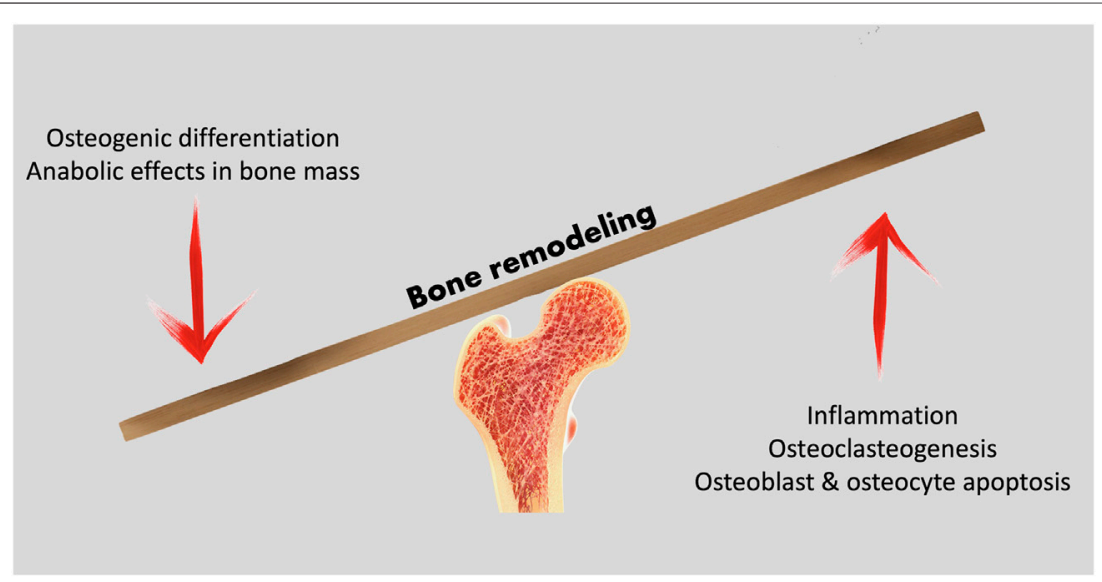

FIGURE 1 | Bone remodeling processes rely on the balance between anabolic and catabolic cell activity to maintain a healthy bone structure, adapted to loading demands. 


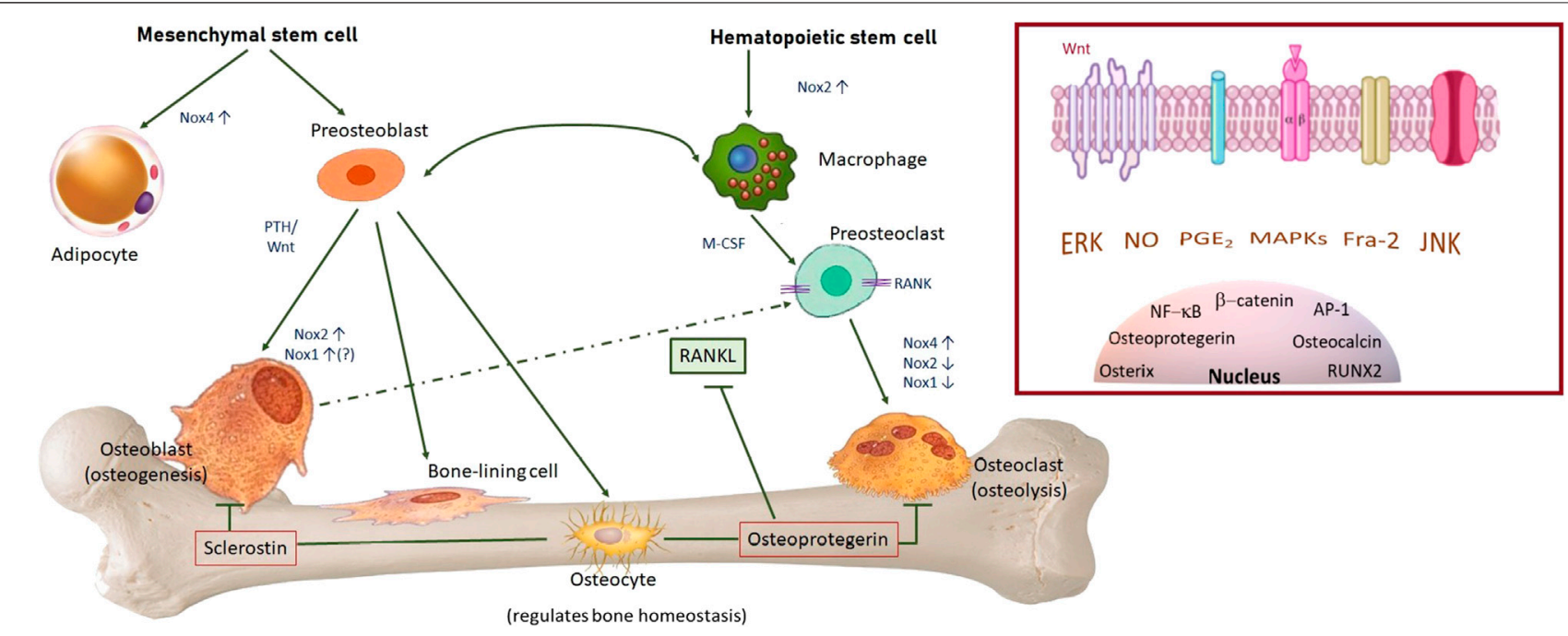

FIGURE 2 | Main cellular populations in bone, role and NADPH oxidases isoforms expressed, paramount for ROS-mediated differentiation, activity and fate of osteoblasts and osteoclasts. Under mechanical loading, Nox2 is activated in osteocytes, producing ROS and leading to ROS-mediated decrease in sclerostin and activation of the Wnt/ $\beta$-catenin pathway. Bone marrow macrophages express Nox2. During RANKL-induced osteoclast differentiation, Nox2 is suppressed and Nox4 is upregulated by RANKL. Overexpression of Nox4 increases adipogenesis and not osteogenesis. Osteogenic differentiation involves parathormone (PTH) and Wnt signalling pathways. Nox1 and Nox2 are inducible and thought to have a role in osteoblast proliferation and differentiation. Osteoprotegerin expression is induced by physiological mechanical stimulation and inhibits osteoclasteogenesis. Nox4 synthetizes $\mathrm{H}_{2} \mathrm{O}_{2}$ and drives cell differentiation. Insert: bone cell regulation and mechanotransduction involves several ROS-sensitive pathways.

regulator of bone homeostasis (Sun et al., 2015; Wegner and Haudenschild, 2020). Nuclear respiratory factor 1 (Nrf1) is also a transcription factor, of the same family, and known to regulate the antioxidant response elements-driven target genes (Xing et al., 2007). Both have been linked to the expression and activity of Osterix and RUNX, both associated with osteoblast differentiation and bone metabolism regulation (Xing et al., 2007; Sun et al., 2015).

While ROS generation in inflammatory processes arises mainly from the mitochondria, fine-tuned ROS generation, both in physiologic and pathologic conditions, is originated mainly by members of the Nox family; these differ in cellular location, activation mode and type of ROS they produce; Nox1/2 produce $\bullet \mathrm{O}_{2}^{-}$and Nox4 produces $\mathrm{H}_{2} \mathrm{O}_{2}$, contributing to modulate the formation, activity, and survival of osteoblasts and osteoclasts (Figure 2).

Osteocyte differentiation has been associated with increased Nrf2 activity, that responding to raised ROS levels, drives the transcription of osteocyte-specific genes. This is likely caused by increased mitochondrial numbers associated to glucose deprivation. Nutrient deprivation likely results from the osteoblast entrapment in the mineralized bone matrix, triggering the osteoblast-osteocyte transition (Sánchez-deDiego et al., 2021). Thus, cell fate (osteocytogenesis or apoptosis) is again finely tuned by the cell redox state.

$\mathrm{NO}$ is essential to control and balance periodontal stem cell differentiation, promoting osteogenic differentiation rather than adipogenic (Yang et al., 2018), and has anabolic effects in bone, promoting osteoblast differentiation and glucose metabolism. NO production depends on arginine synthesis via the enzyme argininosuccinate lyase and its production is negatively modulated by control mechanisms such as nitric oxide synthase binding by caveolin-1 (Jin et al., 2021). NO release may be triggered by RANKL; since inhibition of RANKL-induced $\mathrm{NO}$ increases osteoclastogenesis and bone resorption, osteoclastogenesis in response to RANKL is probably diminished by NO production (Huang et al., 2017) (Figure 3).

The transcription factor activator protein 1 (AP-1) is implicated in differentiation mechanisms and cell activity regulation (Garces de Los Fayos Alonso et al., 2018; Bejjani et al., 2019). It is formed by c-Fos and c-Jun proteins and its activity is redox-regulated (Abate et al., 1990). Intermediate levels of ROS activate the AP-1 transcription factor and the NF- $\kappa$ B signaling pathway, while low levels of ROS stimulate Nrf2. NF- $\kappa \mathrm{B}$ activation triggers osteoclastogenesis and increased levels of inflammatory cytokines (Le Rossignol et al., 2018; Lepetsos et al., 2019). NO may also suppress the DNA-binding activity of AP-1 through S-glutathionylation; NO modifies the two cysteine residues contained in the DNA binding module of c-Jun (Klatt et al., 1999; Lepetsos et al., 2019), supporting NO anabolic effects on bone mass. High AP-1 is, thus, one of the transcription factors intervening in osteoclastogenesis and in the regulation of osteoclast activity (Wagner, 2010; Pang et al., 2019). c-Jun and AP-1 are also involved in osteogenic differentiation of mesenchymal stem cells, namely through increased RUNX2 expression (Fu et al., 2019). Under or over-expression of Fra2, a Fos-related protein of the AP-1 family, results in structural and functional bone anomalies. Fra-2 promotes osteoblast differentiation, collagen, and osteocalcin production, apparently in detriment of adipocyte formation, without affecting osteoclastogenesis (Bozec et al., 2010). Recent studies suggest reduced ROS production inhibits osteoclast 


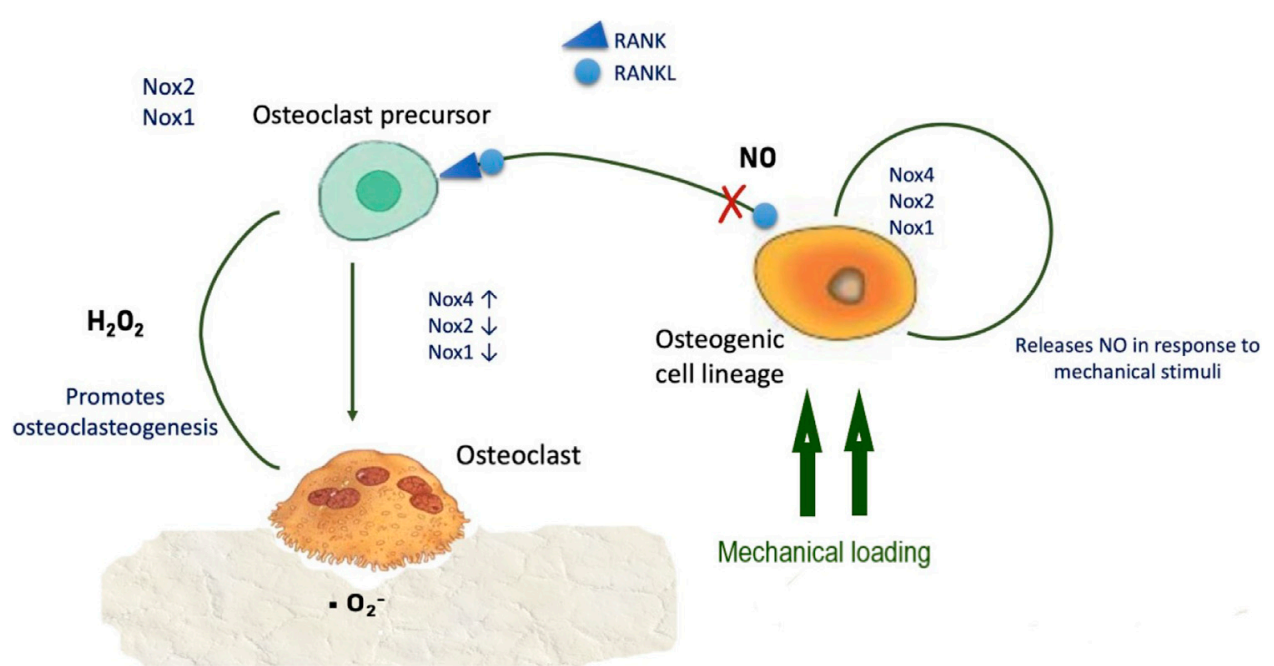

FIGURE 3 | ROS synthesis and regulation of osteogenic and osteoclastic cells. Physiological levels of NO inhibit RANK/RANKL-mediated osteoclastogenesis.

differentiation and bone resorption (Ohyama et al., 2018), via a decrease in mitogen-activated protein kinases (MAPKs) extracellular signal-regulated Erk and the activation of c-Jun $\mathrm{N}$-terminal kinases (Erk). The elevation of intracellular ROS levels leads to the activation of MAPKs, such as p38, Erk, and JNK, by oxidative modifications of MAPK signaling proteins and through inactivation of the MAPK phosphatases (MKPs). The latter inactivate MAPKs by dephosphorylation. MKPs may be inactivated by oxidation of cystein residues in the enzyme catabolic site. However, MKPs induction or inactivation by ROS is likely dependent on ROS levels. ROS may simultaneously activate MAPKs and induce MPK expression (Son et al., 2013).

$\mathrm{H}_{2} \mathrm{O}_{2}$ promotes osteoclast formation and osteoblast apoptosis, inhibiting osteoblast proliferation, while $\bullet \mathrm{O}_{2}{ }^{-}$increases with osteoclastic resorption activity, prompted by parathormone and interleukine 1 (Garrett et al., 1990; Lean et al., 2005; Dai et al., 2017).

Oxidative stress impairment of osteoblast differentiation and osteogenic capacity has been associated with bone loss in aging. In the aging mice, the expression of Forkhead box $\mathrm{O}$ (FoxO) target genes increases, while the expression of Wnt target genes decreases, due to interference with the $\mathrm{Wnt} / \beta$-Catenin pathway (Almeida et al., 2007). The FoxO transcription factors regulate the expression of genes coding for proteins with antioxidant activity. FoxO activity may be regulated by posttranslational modifications, protein-protein interactions, and also by mechanisms regulating FoxO gene transcription and mRNA stability. FoxO transcription factors are subject to redox regulation through phosphorylation (through MAPKs activity) and acetylation and ubiquitination of the lysine residues in FoxO proteins (Klotz et al., 2015). $\beta$-catenin is required for FoxO transcription, and this binding is stimulated by ROS, thus decreasing $\beta$-catenin availability, to the detriment of the $\mathrm{Wnt} / \beta$-catenin signaling pathway. In aging mice, NAD+ is decreased. NAD + -dependent Sirtuin 1 deacetylates FoxOs and $\beta$-catenin, increasing Wnt pathway expression in osteoblast progenitors (Kim and Park., 2021). ROS interference in osteoblastogenesis and osteoclastogenesis is also present in pathological conditions such as osteoporosis and arthritis (Agidigbi and Kim, 2019; Wang Y. N. et al., 2021).

The different bone cell types communicate through $\mathrm{Cx} 43$ gap junction channels and hemichannels; the $\mathrm{Cx} 43$ gap junction channels are central to mechanotransduction and bone remodeling. Under oxidative stress or diminished antioxidative defense conditions, such as osteoporosis due to aging, estrogen deficiency or glucocorticoid treatment, $\mathrm{Cx} 43$ expression is decreased. The opening of $\mathrm{Cx} 43$ hemichannels has a protective role against osteocyte cell damage by ROS (Hua et al., 2021) and protects the trabecular bone against catabolic effects associated with estrogen deficiency (Ma et al., 2019).

\section{BONE DEVELOPMENT AND HEALING: THE ROLE OF OXIDATIVE STRESS}

There is evidence that redox states within the embryo shape gene expression patterns through redox-sensitive transcription factors (Figure 4), as has been theorized; changes in redox state may also contribute to spatial differences in cell activity, contributing to cell differentiation, and intimately related to the production of necessary energy for survival and growth (Harvey et al., 2002). Life emerged and evolved in an environment with varying levels of oxygen, often hypoxic, and redox/hypoxia seems to be an ancient and well-conserved regulatory pathway, fundamental for development and regeneration (Loenarz et al., 2011; Coffman and Su, 2019). Mammalian embryos develop in a hypoxic environment; hypoxia inducible factor (HIF) has several isoforms from which HIF1 is the most relevant in the context of skeletal tissues. HIF consists of two subunits, one unstable (HIF- $\alpha)$, and one stable (HIF- $\beta$ ); it is a transcription factor intervening in the cell response to hypoxia. Oxygen 


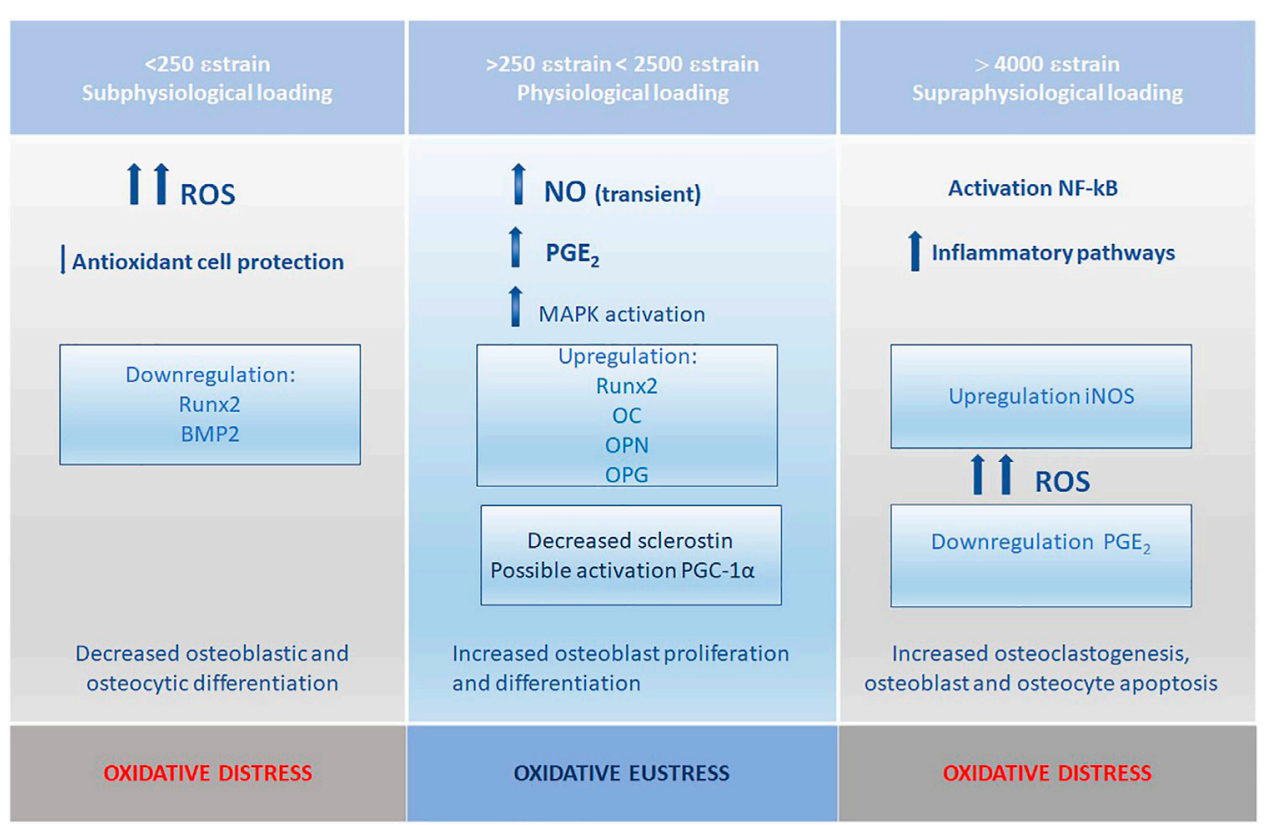

FIGURE 4 | Redox state and strain levels; persistent sub or supraphysiological mechanical stimulation leads to increased ROS levels and deregulation of the bone remodeling and formation processes.

concentrations regulate the level and activity of HIF- $\alpha$ through hydroxylation of prolyl residues, by members of the prolyl hydroxylase domain (PHD) family and asparaginyl hydroxylase (FIH) (Kaelin and Ratcliffe, 2008). Under normal oxygen conditions, the hydroxylation of HIF- $\alpha$ decreases its transcriptional activity. Under hypoxia, the hydroxylation of HIF- $\alpha$ is inhibited, since it needs oxygen and iron. HIF- $\alpha$ becomes abundant in the cytoplasm, translocates to the nucleus, and dimerizes with HIF- $\beta$ subunit. The dimer then binds to hypoxia-response elements (HREs), promoting the expression of target genes that modulate cell response to hypoxia (Coffman and Su, 2019). The formation of vertebrates' endochondral bone is initiated by the formation of avascular mesenchymal condensations, followed by chondrogenesis, a process in which HIF-1a is required for chondrocyte differentiation, survival, and proliferation (Cordeiro and Tanaka, 2020). HIF has been linked to upregulation of angiogenesis and secretion of extracellular matrix proteins, including collagen type II (Wan et al., 2010; Bentovim et al., 2012). Interestingly, HIF-1 $\alpha$ is activated by NO under normoxic conditions (Wan et al., 2010).

Mesenchymal stem cell proliferation and osteogenic differentiation also depend on other transcriptional factors such as Runx2, Osterix, and FoxO, as previously discussed. The above-mentioned transcriptional factors, all directly or indirectly regulated by oxygen and redox environment, do not operate in tightly separated pathways, contributing to the redundancy and multi-point pathway control of cell fate and stress response.

Gene expression is also directly controlled by oxygen levels since histone demethylases are oxygen-dependent, in an oxygen-mediated mechanism that seems to precede the HIF pathway (Coffman and Su, 2019).

Adequate nutrient and oxygen support is, therefore, fundamental for cell fate determination, as it is widely recognized in clinical practice. Preserving vascularization and blood supply to fracture sites is a priority during the surgical approach and osteosynthesis. The mechanical stability of the fracture site is determinant for the healing mode. In stabilized, non-complicated fractures, mesenchymal stem cells differentiate directly into osteoblasts, and fracture healing ensues by intramembranous ossification while if the fracture is unstable, the bone heals through endochondral ossification (Miclau et al., 2017). In most clinical situations, both ossification modes occur. After a bone fracture, there is always some degree of disruption of the blood supply, leading to local lower oxygen levels. This hypoxic local environment is a powerful trigger for neovascularization through the HIF-1 pathway and the expression of vascular endothelial growth factor (VEGF) (Shen et al., 2009). Hypoxia also induces bone morphogenetic protein 2 (BMP2) expression by mesenchymal stem cells through a pathway independent from HIF-1; BMP2 is a powerful inductor of osteo and chondrogenesis, and its induction happens through a redox-sensitive mechanism; if hypoxia is prevented, BMP2 secretion is inhibited and healing is impaired, as happens in fracture non-union (Muinos-López et al., 2016). BMP2 secretion and HIF1 activation seem to overlap. The hypoxia, although necessary, should be transient; normoxia conditions are necessary for collagen cross-linking and stabilization of the basement membrane of the new vascular network that will ensure adequate perfusion of the site (Miclau et al., 2017). NO has a recognized role in fracture 
healing; NO mediates vasodilation, essential for increased blood flow to the fracture site but also for the vascular response, bone formation, and resorption during the remodelling phase (Ding et al., 2018).

\section{OXIDATIVE STRESS MECHANISMS IN DISEASE: HOW IS BONE AFFECTED}

ROS are increased in inflammatory conditions and in a number of non-inflammatory systemic diseases that impact bone metabolism. However, ROS-sensitive mechanisms are also essential for normal fracture healing. Research has been focused on the effects of the superoxide anion and hydrogen peroxide on bone cell function and bone remodeling (Wauquier et al., 2009), but other ROS, as well as the antioxidant systems, are also relevant in disease processes.

Fracture non-union is a frequent, painful, complication of bone fractures, deleterious to patient wellbeing. The work developed by Muinos-López et al. (Muinos-López et al., 2016) suggests that although hypoxia is fundamental for initiation of the fracture healing process, factors scavenging ROS are critical for in early phases and mesenchymal stem cells redox state is determinant. Decreased BMP-2a impairs MSC differentiation and delays cartilage mineralization while elevated metalloproteinases contribute to BMP degradation, as reviewed by Ding et al. (Ding et al., 2018). When considering ROS, although the beneficial role of $\mathrm{NO}$ is recognized, it is also known that NO levels are increased in hypertrophic nonunion calluses, suggesting $\mathrm{NO}$ is part of the molecular pathogenesis of nonunion, a hypothesis also supported by the altered levels of the amino acids associated with NO metabolism in atrophic non-union calluses, with arginine availability seemingly a limiting factor (Wijnands et al., 2012). NOSknockout mice show impaired fracture healing, through deregulation of arginine-NO metabolism, paired with increased neutrophil influx to the fracture site; this study focused on the activity of NOS2 and NOS3, not of NOS1, the most relevant for the latter remodeling phase (Meesters et al., 2016).

Osteoarthritis (OA) is the most common joint disorder and affects both articular cartilage and subchondral bone. Its etiology is multifactorial but includes ROS overproduction, associated with Nox4 (Drevet et al., 2018), affection intracellular signaling, impairs chondrocyte and matrix metabolism, contributes to inflammation and subchondral bone lesions. The mechanisms by which ROS are involved in the pathogenesis of the articular cartilage lesions are better characterized than those concerning the subchondral bone. In OA, a central role is played by the NF$\kappa \mathrm{B}$ transcription factors family. The NF- $\kappa B$ dimers, when able to translocate from the cytoplasm into the nucleus, regulate the expression of proinflammatory cytokines, immunomodulatory proteins, and molecules vital for cell adhesion and proliferation. NF- $\kappa B$ is redox-sensitive and its activity may be increased or inhibited by ROS, following oxidation or S-glutathionylation of redox-sensitive cysteine residues, depending on the level of ROS, the types of stimuli, and the cell type (Lepetsos et al.,
2019). NF-kB may also regulate Nrf2 transcription and activity, affecting the redox balance (Choi et al., 2019; Lepetsos et al., 2019). Chondrocytes treated with advanced oxidation protein products increase the expression of interleukin (IL)- $1 \beta$ and tumor necrosis factor (TNF)- $\alpha$, known to prompt articular degenerative changes; this happens via the Nox4-dependent and p38-MAPK mediated pathway (Liao et al., 2020). Mechanical stress has been associated with the development of $\mathrm{OA}$, via activation of interleukin- $1 \beta$, tumour necrosis factor- $\alpha$, nuclear factor kappa$B$, Wnt, transforming growth factor- $\beta$, microRNAs pathways, and the oxidative stress pathway. Involved receptors include integrin, ion channel receptors, hydrogen peroxide-inducible clone-5, Gremlin-1, and transient receptor potential channel 4 (Fang et al., 2021).

Rheumatoid arthritis (RA) is a chronic systemic autoimmune disease, arising from the synovia; it may course with synovial hyperplasia, cartilage damage, bone erosion, and systemic repercussions. The subchondral bone may become eroded as a result of increased numbers of osteoclasts and decreased osteoblasts (Guo et al., 2018). RA is associated with high levels of ROS and local bone loss as a consequence of inflammation. Redox-sensitive transcription factors, including NF- $\mathrm{kB}, \mathrm{AP}-1$, and $\mathrm{Nrf2}$, are involved in the pathogenesis of RA (Le Rossignol et al., 2018). NOX4 is the only NOX isoform found in human chondrocytes and it may be central in cartilage degradation and development of osteoarthritis (Agidigbi and Kim, 2019).

Osteoporosis, another multifactorial progressive disorder, is not inflammatory in nature, as opposed to OA and RA. However, there is increasing evidence that redox imbalance is implicated. In patients with post-menopausal osteoporosis, plasma total oxidative status and oxidative stress index were significantly higher than in healthy controls, and total antioxidant status was lower (Altindag et al., 2008). NOX4 is involved in bone loss and represents a potential therapeutic target for the treatment of osteoporosis. Inhibition of Nox4 activity attenuates osteoclastogenesis, which is accompanied by impaired activation of RANKL-induced NFAT-1 (nuclear factor of activated $\mathrm{T}$ cells 1) and c-Jun (Schröder, 2015). NFATc1 signaling could be the key downstream event in RANKLmediated ROS signaling (Agidigbi and Kim, 2019). Age-related osteoporosis is also related to a deficit in osteoblasts, which decline in numbers with aging. In aged mice, decreased levels of NAD+ were described, associated with increased acetylation of the FoxO1/ $\beta$-catenin pathway and markers of cell senescence. Reduction of NAD + levels in osteoprogenitor cultures from young mice inhibited osteoblastogenesis in a FoxO-dependent manner (Kim et al., 2021).

Diabetes mellitus (DM) is an important cause of impaired bone healing and delayed fracture healing; recent studies suggest high glucose concentrations are deleterious for osteoclastogenesis and osteoclast function (Hu et al., 2019). High glucose levels also suppress osteogenic differentiation in vitro by promoting the production of ROS and downregulating the anti-oxidative defense enzyme superoxide dismutase; these effects are reversed by the use of antioxidants (Dong et al., 2017). Low bone mineral density has been reported associated with DM (Adil 
et al., 2015) and differences may be more marked in postmenopausal women with DM (Halper-Stromberg et al., 2020). These anomalies have been associated with increased ROS by altered energy metabolic pathways (Bacevic et al., 2017; Dong et al., 2017; Korac et al., 2021).

The skeleton is affected by primary and secondary neoplasia. As in healthy tissue, ROS are important determinants of cancer biology and behavior. Cancer cells produce ROS and these may act promoting cell survival and proliferation or cell death. In osteosarcoma, the knockdown of NOX2 significantly suppressed ROS generation, inducing apoptosis as a result (Kitamoto et al., 2018). Nrf2 is related to a poor prognosis in osteosarcoma (Park et al., 2012); Nrf2 heightened activity protects cells against apoptosis, even following DNA damage which is not adequately corrected; tumorigenesis may also occur due to metabolic changes initiated by Nrf2 activation or by signaling changes that are Nrf2-dependent (Gunne et al., 2020). Nfr2 promotes cancer development after it is established, a change to its protective role in the physiological status. Nfr2 also modulates the immune response; immune suppression in cancer depends mainly on regulatory $\mathrm{T}$ (Treg) cells and myeloid-derived suppressor cells (MDSCs) (He et al., 2020). The inhibition of the cytoprotective, antioxidant $\mathrm{Nfcr} 2$ pathways has been shown to be a highly promising therapeutic solution for numerous tumors, including osteosarcoma (Lu et al., 2018; Panieri and Saso, 2019; Telkoparan-Akillilar et al., 2021). Solute carrier 25 family member 10 (SLC25A10), or dicarboxylate carrier, also is important for redox homeostasis. SLC25A10 levels are elevated in human osteosarcoma tissues, compared with normal bone tissues; higher SLC25A10 levels have also been positively correlated with metastization (Wang et al., 2020).

\section{OXIDATIVE STRESS AND BONE MECHANOBIOLOGY}

Adequate mechanical stimulation is of paramount importance for bone homeostasis, remodeling, and formation. As postulated by Wolff's law, bone adapts to functional loads conditions, in such a way that its mass and architecture are optimal; the magnitude and distribution of resulting strains are decisive (Rubin and Lanyon, 1984). Bone adaptation occurs to maintain the local strain; increased bone strain from physical activity may induce bone gain, if within the elastic deformation interval, while decreased bone strain results in bone loss (Sugiyama et al., 2016). However, mechanical loading influences more than bone mass and microarchitecture, since loading also increases bone material strength in post-menopausal healthy women; the effects of the daily one-leg jump, in increasing number for 3 months, was present on the loaded tibial bone when compared to contralateral control tibia (Sundh et al., 2018).

Supraphysiological mechanical forces induce inflammation through activation of the NF- $\mathrm{B}$ cascade, known to be redoxsensitive (Chatterjee and Fisher, 2014). Excessive mechanical loading induces an increase in ROS, activating NF- $\kappa B$ and cartilage degeneration (Chang et al., 2019), further supporting the existence of a ROS-mediated mechanism in damage associated with mechanical stress. Lack of sufficient mechanical stimuli induces altered mitochondrial function. Microgravity conditions inhibit the proliferation of mesenchymal stem cells and osteogenic differentiation through downregulation of a multitude of genes, including Runx2 and BMP2 (Li et al., 2019). Microgravity deeply affects osteoblast mitochondrial energy potential, inducing an oxidative stress response, with decreased oxidized glutathione and antioxidant enzymes (Michaletti et al., 2017); similar interference with the glycolysis pathways, resulting in downregulation of osteocytic genes, was described in osteocytic cell lines under microgravity conditions (Uda et al., 2021). Mechanical unloading increased both intracellular ROS production and the Sod1 expression in bone tissue including bone marrow cells in mice (Morikawa et al., 2013).

However, again ROS effects are dual. Both NO and PG E2 are required in mechanically induced bone formation (Chow et al., 1998; Watanuki et al., 2002) (Figure 4). The nitric oxide synthase has several isoforms: an endothelial isoform (eNOS), extensively expressed in bone on a constitutive basis, and an inducible isoform (iNOS), only expressed in response to inflammatory stimuli and a neuronal NOS (nNOS). The eNOS isoform plays a key role in regulating osteoblast activity and bone formation also mediating bone mechanical stimulation (van't Hof and Ralston, 2001; Schröder, 2015). Osteocytes express NO transporters and a few minutes after a mechanical stimulus, release NO which suppresses bone resorption (Chambers et al., 1999). Increased ROS levels and osteogenic gene expression in MC3T3-E1 osteoblasts, through MAPK activation mediated by ROS, were described after stimulation by low-intensity pulsed ultrasounds; inhibition of ROS attenuated osteogenic gene expression, including Runx2, osteocalcin, and osteopontin (Kaur et al., 2017). It is also recognized that osteocytes transduce mechanical load signals to activate Nox2, producing ROS signals; this response is accompanied by a rapid ROS-mediated decrease in sclerostin levels by lysosomes, allowing activation of the $\mathrm{Wnt} / \beta$-catenin signaling pathway, and bone formation (Schröder, 2015; Gould et al., 2021). However, in endothelial cells, oxidative stress due to unregulated Nox activity leads to altered eNOS function, shifting from $\mathrm{NO}$ production to $\mathrm{O}_{2}{ }^{-}$, further inducing oxidative stress and increasing ROS levels, with subsequent endothelial disfunction (Meza et al., 2019). It is possible that a similar process occurs in bone.

The peroxisome proliferator-activated receptor-gamma, coactivator 1 alpha (PGC-1 $\alpha$ ) is an important regulator of mitochondrial biogenesis, and it regulates ROS metabolism by preventing oxidative stress. In skeletal muscle, its role in mitochondrial homeostasis during differentiation has been recognized. Downregulation of PGC-1a caused impairment of antioxidants expression, accompanied by a significant burst in ROS and oxidative damage to proteins. Mitochondrial mass and function decreased while mitophagy augmented through the ROS/FOXO1 pathway (Baldelli et al., 2014). The PGC-1a anabolic role in bone has been highlighted by a number of in vitro and in vivo studies, as recently reviewed by Buccoliero 
et al., (Buccoliero et al., 2021). Sirtuin 3, a mitochondrial (NAD)dependent deacetylase, is a key regulator of osteoblastic differentiation through regulation of mitochondrial function; its absence reduces the expression of superoxide dismutase 2 (Sod2), a mitochondrial molecule with antioxidant activity that permutes superoxide into the less reactive hydrogen peroxide. PGC-1a stimulates Sirtuin 3 activity on osteogenic differentiation (Buccoliero et al., 2021). How different biophysical stimuli may affect mitochondrial metabolism bone was recently reviewed by (Wang F.-S. et al., 2021). In rat skeletal muscle tissue, the expression of PGC-1 $\alpha$ and HIF-1 $\alpha$ were differently affected by the training regimen (continuous, moderate exercise vs highintensity interval) (Ahmadi et al., 2021). However, regarding bone, there is still limited information on how different loading regimens affect these pathways.

\section{OXIDATIVE STRESS AND ORTHOPEDIC IMPLANTS}

Inflammation and hypoxia are leading conditions that drive oxidative stress (Mittal et al., 2014). Neutrophils, eosinophils, and monocytes/macrophages are able to produce large amounts of ROS such as superoxide and hydrogen peroxide as part of the response to a perceived pathogen invasion or mechanical trauma; the release of ROS may be further stimulated by inflammatory mediators (Hameister et al., 2020).

Following trauma, bone healing is initiated with hematoma formation and acute inflammatory response. Disruption of the vascular and bone structures triggers the release of cytokines, leading to inflammatory cell recruitment, especially neutrophils and macrophages (Bahney et al., 2019). Macrophage differentiation and function are strongly influenced by ROS (Zhang et al., 2013). Interestingly, macrophages present different gene expression patterns and cytokine secretion profiles, depending on whether they were induced in pathological conditions or RANKL-induced M1 macrophages. These were found in vivo close to iNOS + cells (inducible nitric oxide synthase-positive cells), peaking on day 7 during bone healing, suggesting they are NO-dependent, involved in bone formation. M1 macrophages' activity is both influenced and influences the microenvironment (Huang et al., 2017).

Surgical trauma is, thus, a cause of oxidative stress, with its magnitude influenced by pathology and comorbidities (Rosenfeldt et al., 2013; Karachalios et al., 2021). Prior to implantation, patients with orthopedic disease often suffer from conditions that contribute to oxidative stress, affect the local microenvironment, and may condition surgical success and implant performance (Mouthuy et al., 2016). The implant itself may drive further oxidative stress, as well as suffer degradation in consequence (Mouthuy et al., 2016; Borys et al., 2018; Eliaz, 2019). Implant wear products are a known cause for inflammation and ROS generation; ROS are generated by local macrophages, through the NOX signaling pathway, also affecting the NF- $\kappa$ B activation (Chen et al., 2015). Although ROS originate from acute and chronic inflammation, they may further arise from the metal surfaces of implants by reduction reactions, subsequently affecting neighboring cells. In turn, the lower $\mathrm{pH}$ associated with inflammation is a contributor to corrosion phenomena; the resulting increase in released particles will perpetuate inflammation, further implant structural damage, and eventually promote systemic effects (Eliaz, 2019; Hameister et al., 2020). Ferroptosis is a form of controlled cell death that occurs in the presence of iron overload and leads to the formation of lipid ROS (Sharma and Flora, 2021), and its association with peri-implant inflammation and cell death has been suggested (Liu et al., 2020). Likewise, increased local ROS levels, inflammation and metallosis have been associated with titanium alloy implants and tribocorrosion phenomena (Borys et al., 2019; Eliaz, 2019).

The performance of implants is also greatly influenced by protein adsorption to the implant surface, with an effect on its stability, metal ion release, and cell adhesion; the redox balance influences protein-metal interactions; recent studies show $\mathrm{H}_{2} \mathrm{O}_{2}$ impedes the formation of dense protein domains on Ti6Al4V surface, increasing protein adsorption, surface potential and total roughness in Ti6Al4V implant surface (Rahimi et al., 2021).

\section{DISCUSSION}

Oxidative stress has been one of the factors implicated in bone disease, in the loss of biomaterials biocompatibility and function. It is now clear that redox mechanisms are paramount for bone physiology.

A better understanding of the host-implant interplay and the role of reactive species and oxidative stress regarding the fate of implanted biomaterials is necessary.

Comorbidities such as DM, OA, and RA may also contribute to oxidative stress since in all these diseases, ROS are increased and NF- $\kappa \mathrm{B}$ is activated, leading to inflammation and imbalances in the bone coupling processes. Excessive production of ROS in these pathologies results from abnormal oxidative energy metabolism in the mitochondria, the activity of enzymatic complexes like the Nox, or both. Noxs, namely Nox4, are one of the culprits (Wauquier et al., 2009; Korac et al., 2021). DM, OA, and RA may be present prior to the surgical procedure, influencing the local microenvironment and thus, the clinical outcome (Hameister et al., 2020). The implant itself will behave differently in the presence of the disease-induced microenvironment changes, namely by increased metal ion leaching (Arteaga et al., 2021). Hyperlipidemia, frequently present in diabetic patients and in several other diseases, as well as a primary condition, causes overproduction of ROS in vitro, interfering with the $\mathrm{Wnt} / \beta$-Catenin pathway and causing osteoblast dysfunction; in vivo, poor bone formation at the bone-implant interface was observed (Wang Y. N. et al., 2021). Overproduction of ROS may also cause eNOS uncoupling, and a shift from $\mathrm{NO}$ production to $\mathrm{O}_{2}{ }^{-}$, contributing to oxidative distress.

Strategies to curb the deleterious effects of the excess ROS may include implant surface modification by coatings with antioxidant properties or by nanotopographic-modulated 
FoxO activation (Abuid et al., 2021; Huang et al., 2021; Shao et al., 2021); protein adsorption to the implant surface, and subsequent changes in the protein structure influence cell adhesion, metal particles release and ultimately, implant stability (Rahimi et al., 2021).

Biomaterials' selection should considerer their contribution to optimum redox state, as suggested by Sthijns et al. (Sthijns et al., 2021), who evaluated different polymers for a pancreatic islet encapsulation device; cell sensitivity to oxidative stress is variable and essential for cell survival, proliferation, and function (Sthijns et al., 2021), and contributes to avoid chronic inflammation and peri-implantar fibrosis. As reviewed by Sthijns et al. (Sthijns et al., 2018), in tissue engineering approaches, ensuring adequate perfusion of the construct is paramount for cell survival and to avoid increased ROS formation. Several strategies may be pursued to achieve optimum delivery of oxygen while avoiding its toxicity. Developing biomaterials that are able to modulate the redox-balance systems such NADPH oxidase, the Nrf2 or the HIF pathways, is a promising approach (Sthijns et al., 2018).

On the other hand, there is also an increased interest in how the redox state may be used as a stimulus in the development of active implants, tuning their response to the local microenvironment. Redox-responsive biomaterials are being studied for drug delivery, with promising results (Yang et al., 2014; Cheewatanakornkool et al., 2018; Gong et al., 2018; Yu et al., 2020). A bio-inspired approach to infection control through active implant generation of ROS has been tested. In this case, implants were responsive to local pH decreases (Song et al., 2020).

Promoting bone health should also encompass nutrition. The most abundant dietary antioxidants are polyphenols and anthocyanin, present in fruits, vegetables, cereals, dry legumes, chocolate, tea, coffee, and wine. As reviewed by Domazetovic et al. (Domazetovic et al., 2017), antioxidant intake promotes bone health. In animals and selected groups of patients with osteoporosis or inflammatory bone diseases, the use of antioxidants was beneficial for the treatment and prevention of bone loss (Domazetovic et al., 2017). Total dietary antioxidant capacity has been described as inversely associated with the risk of osteoporosis in postmenopausal women and positively associated with bone mass in both pre- and postmenopausal women (Kim and Park, 2021). Eicosapentaenoic acid and docosahexaenoic acid omega-3 fatty acids reduce superoxide production catalyzed by the NADPH oxidase in neutrophils, and there is growing evidence of the benefits of dietary supplementation in lowering the expression of catabolic and inflammatory genes in osteoarthritis. Omega-3 fatty acids reduce oxidative stress and apoptosis via the NF- $\mathrm{kB}$ and the iNOS pathways. Dietary fatty acids may modulate osteogenic differentiation in mesenchymal stem cells by up-regulation in phosphorylation of protein kinase B (Akt) at the plasma membrane (Wauquier et al., 2009; Abshirini et al., 2021).

Literature concerning the role of oxidative stress in mechanotransduction and adaptive responses in endothelial cells is more abundant and allows a better understanding of both the mechanical forces involved and the cellular response (Hsieh et al., 2014; Chatterjee, 2018; Roux et al., 2020; Psefteli et al., 2021). Some studies in cartilage also contribute to the characterization of mechanical loading and redox state alterations (Coleman et al., 2017; Walsh et al., 2019), with evidence supporting that inflammation induced by mechanical loading is ROS-mediated (Kamalathevan et al., 2021).

There is, however, surprisingly limited knowledge on the influence of the biomechanical environment in the bone and bone-implant interface on the redox balance, with some of the information available based on maxillofacial implantology focusing on the effects of the implant itself. It is recognized that ROS boost the inflammatory response and cause both RANKL-induced osteoclastogenesis and osteoblast apoptosis, leading to periprosthetic osteolysis aseptic loosening, the most frequent cause of implant failure (Borys et al., 2018; Ozawa et al., 2020; Galliera et al., 2021). Bone unloading such as observed in disuse and microgravity conditions leads to decreased bone mass and quality, through redox-mediated pathways. Implants, especially metallic ones, have mismatched elastic modulus when compared to the bone, leading to altered loading patterns (stress shielding and stress concentration). Therefore, it would be desirable to understand the contribution of such altered strain levels to oxidative stress reported in numerous studies.

A recent systematic review by Kohli et al. summarizes the considerable overlap between the values of micromotion associated with osseointegrated implants vs failed ones (mean value of micromotion of $112 \pm 176 \mu \mathrm{m}$ for implants showing osteointegration versus $349 \pm 231 \mu \mathrm{m}$ for non-integrated). Other works correlate the implant stability with fibrous tissue formation at the interface, associated with micromotion and lower implant stability (Ramos et al., 2013). The need to consider the loading conditions in detail, combined with the different localized boneimplant geometry, as well as the fundamental mechanobiology mechanisms was also highlighted (Kohli et al., 2021).

The ultimate strength of bone has been reported $25,000 \mu$, with physiologic bone loading ranging from 200 to $2,500 \mu$. Peak strains above 2,500 lead to increased bone mass. However, repeatedly loading bone above $4,000 \mu$ leads to accumulation of damage. Repeated loading within the physiological bone promotes adequate bone remodeling and bone mass maintenance (Roberts et al., 2004; Ramos et al., 2015).

Mechanical unloading downregulates bone mass via intracellular ROS generation (Morikawa et al., 2013). There is evidence that appropriate mechanical stimulation improves antioxidant functions in mesenchymal stem cells and improves bone regeneration, while excessive stretch is deleterious for the cellular antioxidant mechanism. The effect of cyclic stretch at magnitudes of $2.5,5$, and $10 \%$ of human bone marrow-derived mesenchymal stem cells was evaluated in terms of proliferation, ROs, antioxidant enzymes expression, and osteogenesis. Osteogenesis was increased by $5 \%$ stretch, intracellular ROS decreased and the levels of SOD1 and SOD2 increased with 2,5 and $5 \%$ stretch; with the same levels of stretch, ROS scavenging enzymes CAT and GPx1 were also increased. The stretch-induced antioxidant effect was through activation of the adenosine monophosphate-activated protein kinase-silent information regulator type 1 signaling pathway, was more pronounced with $5 \%$ stretch and null under $10 \%$ stretch 
(Chen et al., 2018). It would be useful to understand if PGC-1 $\alpha$ is involved in the increased SOD expression in response to different strain levels in bone cells, as it happens in muscle.

Acknowledging the consequences of the disruption of the loading patterns to bone health, and in face of what is already known, the link between mechanical stimulation and local redox state is apparent. However, although the cellular pathways involving ROS signaling are more and more characterized, the bond of the mechanical environment in relation to the redox state is yet to be fully explored. Computational models may help predict not only ROS production but also ROS scavenging and the influence of inhibitors on ROS production (Gauthier et al., 2013; Pereira et al., 2016). However, although this is a promising approach and several of the existing models were later confirmed experimentally, the incorporation of the modulation of multiple signal-transduction cascades into a dynamic model is still lacking (Pereira et al., 2016). An ideal model should be able to consider spatial effects too, since ROS may originate in different parts of the cell, in addition to predicting ROS damage and signal modulation (Guimera et al., 2019). Haack et al. (Haack et al., 2015) developed a stochastic computational model of canonical $\mathrm{WNT} / \beta$-catenin signaling, combining membrane-related and intracellular processes, including lipid rafts/receptor dynamics as well as Wnt and ROS dependent $\beta$-catenin activation, to investigate its influence in the early phases of neural

\section{REFERENCES}

Abate, C., Patel, L., Rauscher, F. J., 3rd, and Curran, T. (1990). Redox Regulation of Fos and Jun DNA-Binding Activity In Vitro. Science 249, 1157-1161. doi:10.1126/science. 2118682

Abshirini, M., Ilesanmi-Oyelere, B. L., and Kruger, M. C. (2021). Potential Modulatory Mechanisms of Action by Long-Chain Polyunsaturated Fatty Acids on Bone Cell and Chondrocyte Metabolism. Prog. Lipid Res. 83, 101113. doi:10.1016/j.plipres.2021.101113

Abuid, N. J., Urdaneta, M. E., Gattas-Asfura, K. M., Zientek, C., Isusi Silgo, C., Torres, J. A., et al. (2021). Engineering the Multienzymatic Activity of Cerium Oxide Nanoparticle Coatings for the Antioxidant protection of Implants. Adv. Nanobio Res. 1, 2100016. doi:10.1002/anbr.202100016

Adil, C., Aydın, T., Taşpınar, Ö., Kızıltan, H., Eriş, A. H., Hocaoglu, I. T., et al. (2015). Bone mineral Density Evaluation of Patients with Type 2 Diabetes Mellitus. J. Phys. Ther. Sci. 27, 179-182. doi:10.1589/jpts.27.179

Agidigbi, T. S., and Kim, C. (2019). Reactive Oxygen Species in Osteoclast Differentiation and Possible Pharmaceutical Targets of ROS-Mediated Osteoclast Diseases. Ijms 20, 3576. doi:10.3390/ijms20143576

Ahmadi, A., Sheikholeslami-Vatani, D., Ghaeeni, S., and Baazm, M. (2021). The Effects of Different Training Modalities on Monocarboxylate Transporters MCT1 and MCT4, Hypoxia Inducible Factor-1 $\alpha$ (HIF-1 1 ), and PGC-1 $\alpha$ Gene Expression in Rat Skeletal Muscles. Mol. Biol. Rep. 48, 2153-2161. doi:10.1007/s11033-021-06224-0

Almeida, M., Han, L., Martin-Millan, M., O’Brien, C. A., and Manolagas, S. C. (2007). Oxidative Stress Antagonizes Wnt Signaling in Osteoblast Precursors by Diverting $\beta$-Catenin from T Cell Factor- to Forkhead Box O-Mediated Transcription. J. Biol. Chem. 282, 27298-27305. doi:10.1074/ jbc.m702811200

Altindag, O., Erel, O., Soran, N., Celik, H., and Selek, S. (2008). Total Oxidative/ anti-Oxidative Status and Relation to Bone mineral Density in Osteoporosis. Rheumatol. Int. 28, 317-321. doi:10.1007/s00296-007-0452-0

Arteaga, A., Qu, J., Haynes, S., Webb, B. G., LaFontaine, J., and Rodrigues, D. C. (2021). Diabetes as a Risk Factor for Orthopedic Implant Surface Performance: A Retrieval and In Vitro Study. J. Bio Tribo Corros 7, 51. doi:10.1007/s40735021-00486-8 differentiation (Haack et al., 2015). Signaling through this same pathway increases bone mass by the renewal of stem cells, stimulation of preosteoblast replication, osteoblastogenesis, and inhibition of osteoblast and osteocyte apoptosis. So, along with the application of the existing models to bone cells, further developing models integrating mechanotransduction and redox state is a much-needed, logical approach.

In what measure strain, stress, frequency of stimuli, and rest periods are translated into redox state changes, intermediated by the different reactive species, is a major challenge that may be addressed through in-silico approaches, as well as experimentally. However, as every unknown, it also carries a promise of therapeutic applications through multimodal approach, including optimal physical stimuli, adequate antioxidant nutritional support, device selection and modification to minimize oxidative distress and eventually, drugs specifically targeting redox state and redox-sensitive pathways.

\section{AUTHOR CONTRIBUTIONS}

JR: concept, literature analysis, and interpretation, and manuscript writing; AR: literature analysis, and interpretation, contributed to writing and critical revision of the manuscript.

Bacevic, M., Brkovic, B., Albert, A., Rompen, E., Radermecker, R. P., and Lambert, F. (2017). Does Oxidative Stress Play a Role in Altered Characteristics of Diabetic Bone? A Systematic Review. Calcif. Tissue Int. 101, 553-563. doi:10.1007/s00223-017-0327-7

Bahney, C. S., Zondervan, R. L., Allison, P., Theologis, A., Ashley, J. W., Ahn, J., et al. (2019). Cellular Biology of Fracture Healing. J. Orthop. Res. 37, 35-50. doi:10.1002/jor.24170

Baldelli, S., Aquilano, K., and Ciriolo, M. R. (2014). PGC-1 $\alpha$ Buffers ROS-Mediated Removal of Mitochondria during Myogenesis. Cell Death Dis 5, e1515. doi:10.1038/cddis.2014.458

Bejjani, F., Evanno, E., Zibara, K., Piechaczyk, M., and Jariel-Encontre, I (20191872). The AP-1 Transcriptional Complex: Local Switch or Remote Command? Biochim. Biophys. Acta (Bba) - Rev. Cancer 1872, 11-23. doi:10.1016/j.bbcan.2019.04.003

Bentovim, L., Amarilio, R., and Zelzer, E. (2012). HIF1a Is a central Regulator of Collagen Hydroxylation and Secretion under Hypoxia during Bone Development. Development 139, 4473-4483. doi:10.1242/dev.083881

Borys, J., Maciejczyk, M., Antonowicz, B., Kretowski, A., Waszkiel, D., Bortnik, P., et al. (2018). Exposure to Ti4Al4V Titanium Alloy Leads to Redox Abnormalities, Oxidative Stress, and Oxidative Damage in Patients Treated for Mandible Fractures. Oxid. Med. Cel. Longev. 2018, 3714725. doi:10.1155/2018/3714725

Borys, J., Maciejczyk, M., Antonowicz, B., Sidun, J., Świderska, M., and Zalewska, A. (2019). Free Radical Production, Inflammation and Apoptosis in Patients Treated with Titanium Mandibular Fixations-An Observational Study. Front. Immunol. 10, 2662. doi:10.3389/fimmu.2019.02662

Bozec, A., Bakiri, L., Jimenez, M., Schinke, T., Amling, M., and Wagner, E. F. (2010). Fra-2/AP-1 Controls Bone Formation by Regulating Osteoblast Differentiation and Collagen Production. J. Cel Biol. 190, 1093-1106. doi:10.1083/jcb.201002111

Buccoliero, C., Dicarlo, M., Pignataro, P., Gaccione, F., Colucci, S., Colaianni, G., et al. (2021). The Novel Role of PGC1 $\alpha$ in Bone Metabolism. Ijms 22, 4670. doi:10.3390/ijms22094670

Chambers, T. J., Fox, S., Jagger, C. J., Lean, J. M., and Chow, J. W. M. (1999). The Role of Prostaglandins and Nitric Oxide in the Response of Bone to Mechanical Forces. Osteoarthritis and Cartilage 7, 422-423. doi:10.1053/ joca.1998.0231 
Chang, S. H., Mori, D., Kobayashi, H., Mori, Y., Nakamoto, H., Okada, K., et al. (2019). Excessive Mechanical Loading Promotes Osteoarthritis through the Gremlin-1-NF-Kb Pathway. Nat. Commun. 10, 1442-1513. doi:10.1038/ s41467-019-09491-5

Chatterjee, S. (2018). Endothelial Mechanotransduction, Redox Signaling and the Regulation of Vascular Inflammatory Pathways. Front. Physiol. 9, 524. doi:10.3389/fphys.2018.00524

Chatterjee, S., and Fisher, A. B. (2014). Mechanotransduction: Forces, Sensors, and Redox Signaling. Antioxid. Redox Signaling 20, 868-871. doi:10.1089/ars.2013.5753

Cheewatanakornkool, K., Niratisai, S., Dass, C. R., and Sriamornsak, P. (2018). Redox-responsive Microbeads Containing Thiolated Pectin-Doxorubicin Conjugate Inhibit Tumor Growth and Metastasis: An In Vitro and In Vivo Study. Int. J. Pharmaceutics 545, 1-9. doi:10.1016/j.ijpharm.2018.04.052

Chen, W., Li, Z., Guo, Y., Zhou, Y., Zhang, Z., Zhang, Y., et al. (2015). Wear Particles Promote Reactive Oxygen Species-Mediated Inflammation via the Nicotinamide Adenine Dinucleotide Phosphate Oxidase Pathway in Macrophages Surrounding Loosened Implants. Cell. Physiol. Biochem. 35, 1857-1867. doi:10.1159/000373996

Chen, X., Yan, J., He, F., Zhong, D., Yang, H., Pei, M., et al. (2018). Mechanical Stretch Induces Antioxidant Responses and Osteogenic Differentiation in Human Mesenchymal Stem Cells through Activation of the AMPK-SIRT1 Signaling Pathway. Free Radic. Biol. Med. 126, 187-201. doi:10.1016/ j.freeradbiomed.2018.08.001

Choi, M.-C., Jo, J., Park, J., Kang, H. K., and Park, Y. (2019). NF-B Signaling Pathways in Osteoarthritic Cartilage Destruction. Cells 8, 734. doi:10.3390/cells8070734

Chow, J. W. M., Fox, S. W., Lean, J. M., and Chambers, T. J. (1998). Role of Nitric Oxide and Prostaglandins in Mechanically Induced Bone Formation. J. Bone Miner. Res. 13, 1039-1044. doi:10.1359/jbmr.1998.13.6.1039

Coffman, J. A., and Su, Y.-H. (2019). Redox Regulation of Development and Regeneration. Curr. Opin. Genet. Dev. 57, 9-15. doi:10.1016/j.gde.2019.06.002

Coleman, M., Brouillette, M., Andresen, N., Oberley-Deegan, R., and Martin, J. (2017). Differential Effects of Superoxide Dismutase Mimetics after Mechanical Overload of Articular Cartilage. Antioxidants 6, 98. doi:10.3390/antiox6040098

Cordeiro, I. R., and Tanaka, M. (2020). Environmental Oxygen Is a Key Modulator of Development and Evolution: From Molecules to Ecology: Oxygen-Sensitive Pathways Pattern the Developing Organism, Linking Genetic and Environmental Components during the Evolution of New Traits. Bioessays 42, e2000025S. doi:10.1002/bies.202000025

Dai, P., Mao, Y., Sun, X., Li, X., Muhammad, I., Gu, W., et al. (2017). Attenuation of Oxidative Stress-Induced Osteoblast Apoptosis by Curcumin Is Associated with Preservation of Mitochondrial Functions and Increased Akt-Gsk3 $\beta$ Signaling. Cel. Physiol. Biochem. 41, 661-677. doi:10.1159/000457945

Darden, A. G., Ries, W. L., Wolf, W. C., Rodriguiz, R. M., and Key, L. L., Jr (1996). Osteoclastic Superoxide Production and Bone Resorption: Stimulation and Inhibition by Modulators of NADPH Oxidase. J. Bone Miner. Res. 11, 671-675. doi:10.1002/jbmr.5650110515

Ding, Z.-C., Lin, Y.-K., Gan, Y.-K., and Tang, T.-T. (2018). Molecular Pathogenesis of Fracture Nonunion. J. Orthopaedic Translation 14, 45-56. doi:10.1016/ j.jot.2018.05.002

Domazetovic, V., Marcucci, G., Iantomasi, T., Brandi, M. L., and Vincenzini, M. T. (2017). Oxidative Stress in Bone Remodeling: Role of Antioxidants. ccmbm 14, 209-216. doi:10.11138/ccmbm/2017.14.1.209

Dong, K., Hao, P., Xu, S., Liu, S., Zhou, W., Yue, X., et al. (2017). Alpha-Lipoic Acid Alleviates High-Glucose Suppressed Osteogenic Differentiation of MC3T3-E1 Cells via Antioxidant Effect and PI3K/Akt Signaling Pathway. Cel. Physiol. Biochem. 42, 1897-1906. doi:10.1159/000479605

Drevet, S., Gavazzi, G., Grange, L., Dupuy, C., and Lardy, B. (2018). Reactive Oxygen Species and NADPH Oxidase 4 Involvement in Osteoarthritis. Exp. Gerontol. 111, 107-117. doi:10.1016/j.exger.2018.07.007

Eliaz, N. (2019). Corrosion of Metallic Biomaterials: A Review. Materials 12, 407. doi: $10.3390 / \mathrm{ma1} 2030407$

Fang, T., Zhou, X., Jin, M., Nie, J., and Li, X. (2021). Correction to: Molecular Mechanisms of Mechanical Load-Induced Osteoarthritis. Int. Orthopaedics (Sicot) 45, 1661. doi:10.1007/s00264-021-05055-9

Frias, C., Reis, J., Capela e Silva, F., Potes, J., Simões, J., and Marques, A. T. (2010). Polymeric Piezoelectric Actuator Substrate for Osteoblast Mechanical Stimulation. J. Biomech. 43, 1061-1066. doi:10.1016/j.jbiomech.2009.12.010
Fu, L., Peng, S., Wu, W., Ouyang, Y., Tan, D., and Fu, X. (2019). LncRNA HOTAIRM1 Promotes Osteogenesis by Controlling JNK/AP-1 Signalling-mediated RUNX2 Expression. J. Cel. Mol. Med. 23, 7517-7524. doi:10.1111/jcmm.14620

Galliera, E., Massaccesi, L., Banfi, G., De Vecchi, E., Ragone, V., and Corsi Romanelli, M. M. (2021). Effect of Oxidative Stress on Bone Remodeling in Periprosthetic Osteolysis. Clinic Rev. Bone Miner Metab. doi:10.1007/s12018021-09278-7

Garces de Los Fayos Alonso, I., Liang, H.-C., Turner, S., Lagger, S., Merkel, O., and Kenner, L. (2018). The Role of Activator Protein-1 (AP-1) Family Members in CD30-Positive Lymphomas. Cancers 10, 93. doi:10.3390/cancers10040093

Garrett, I. R., Boyce, B. F., Oreffo, R. O., Bonewald, L., Poser, J., and Mundy, G. R. (1990). Oxygen-derived Free Radicals Stimulate Osteoclastic Bone Resorption in Rodent Bone In Vitro and In Vivo. J. Clin. Invest. 85, 632-639. doi:10.1172/jci114485

Gauthier, L. D., Greenstein, J. L., Cortassa, S., O’Rourke, B., and Winslow, R. L. (2013). A Computational Model of Reactive Oxygen Species and Redox Balance in Cardiac Mitochondria. Biophysical J. 105, 1045-1056. doi:10.1016/j.bpj.2013.07.006

Gong, T., Liu, T., Zhang, L., Ye, W., Guo, X., Wang, L., et al. (2018). Design RedoxSensitive Drug-Loaded Nanofibers for Bone Reconstruction. ACS Biomater. Sci. Eng. 4, 240-247. doi:10.1021/acsbiomaterials.7b00827

Gould, N. R., Williams, K. M., Joca, H. C., Torre, O. M., Lyons, J. S., Leser, J. M., et al. (2021). Disparate Bone Anabolic Cues Activate Bone Formation by Regulating the Rapid Lysosomal Degradation of Sclerostin Protein. Elife 10, e64393. doi:10.7554/eLife.64393

Guimera, A. M., Shanley, D. P., and Proctor, C. J. (2019). Modelling the Role of Redox-Related Mechanisms in Musculoskeletal Ageing. Free Radic. Biol. Med. 132, 11-18. doi:10.1016/j.freeradbiomed.2018.09.013

Gunne, S., Heinicke, U., Parnham, M. J., Laux, V., Zacharowski, K., and von Knethen, A. (2020). Nrf2-A Molecular Target for Sepsis Patients in Critical Care. Biomolecules 10, 1688. doi:10.3390/biom 10121688

Guo, Q., Wang, Y., Xu, D., Nossent, J., Pavlos, N. J., and Xu, J. (2018). Rheumatoid Arthritis: Pathological Mechanisms and Modern Pharmacologic Therapies. Bone Res. 6, 15. doi:10.1038/s41413-018-0016-9

Haack, F., Lemcke, H., Ewald, R., Rharass, T., and Uhrmacher, A. M. (2015). Spatio-temporal Model of Endogenous ROS and Raft-dependent WNT/betacatenin Signaling Driving Cell Fate Commitment in Human Neural Progenitor Cells. Plos Comput. Biol. 11, e1004106. doi:10.1371/journal.pcbi.1004106

Halper-Stromberg, E., Gallo, T., Champakanath, A., Taki, I., Rewers, M., Snell-Bergeon, J., et al. (2020). Bone Mineral Density across the Lifespan in Patients with Type 1 Diabetes. J. Clin. Endocrinol. Metab. 105, 746-753. doi:10.1210/clinem/dgz153

Hameister, R., Kaur, C., Dheen, S. T., Lohmann, C. H., and Singh, G. (2020). Reactive Oxygen/nitrogen Species (ROS/RNS) and Oxidative Stress in Arthroplasty. J. Biomed. Mater. Res. 108, 2073-2087. doi:10.1002/jbm.b.34546

Harvey, A., Kind, K., and Thompson, J. (2002). REDOX Regulation of Early Embryo Development. Reproduction 123, 479-486. doi:10.1530/rep.0.1230479

He, F., Ru, X., and Wen, T. (2020). NRF2, a Transcription Factor for Stress Response and beyond. Ijms 21, 4777. doi:10.3390/ijms21134777

Hsieh, H.-J., Liu, C.-A., Huang, B., Tseng, A. H., and Wang, D. L. (2014). Shearinduced Endothelial Mechanotransduction: the Interplay between Reactive Oxygen Species (ROS) and Nitric Oxide (NO) and the Pathophysiological Implications. J. Biomed. Sci. 21, 3. doi:10.1186/1423-0127-21-3

Hu, Z., Ma, C., Liang, Y., Zou, S., and Liu, X. (2019). Osteoclasts in Bone Regeneration under Type 2 Diabetes Mellitus. Acta Biomater. 84, 402-413. doi:10.1016/j.actbio.2018.11.052

Hua, R., Zhang, J., Riquelme, M. A., and Jiang, J. X. (2021). Connexin Gap Junctions and Hemichannels Link Oxidative Stress to Skeletal Physiology and Pathology. Curr. Osteoporos. Rep. 19, 66-74. doi:10.1007/s11914-020-00645-9

Huang, J., Li, R., Yang, J., Cai, M., Lee, Y., Wang, A., et al. (2021). Bioadaptation of Implants to In Vitro and In Vivo Oxidative Stress Pathological Conditions via Nanotopography-Induced FoxO1 Signaling Pathways to Enhance Osteoimmunal Regeneration. Bioactive Mater. 6, 3164-3176. doi:10.1016/j.bioactmat.2021.02.023

Huang, R., Wang, X., Zhou, Y., and Xiao, Y. (2017). RANKL-induced M1 Macrophages Are Involved in Bone Formation. Bone Res. 5, 17019. doi:10.1038/boneres.2017.19

Intemann, J., De Gorter, D. J. J., Naylor, A. J., Dankbar, B., and Wehmeyer, C. (2020). Importance of Osteocyte-Mediated Regulation of Bone Remodelling in Inflammatory Bone Disease. Swiss Med. Wkly 150, w20187. doi:10.4414/smw.2020.20187

Jin, Z., Kho, J., Dawson, B., Jiang, M.-M., Chen, Y., Ali, S., et al. (2021). Nitric Oxide Modulates Bone Anabolism through Regulation of Osteoblast Glycolysis and Differentiation. J. Clin. Invest. 131, e138935. doi:10.1172/JCI138935 
Kaelin, W. G., Jr, and Ratcliffe, P. J. (2008). Oxygen Sensing by Metazoans: the central Role of the HIF Hydroxylase Pathway. Mol. Cel 30, 393-402. doi:10.1016/j.molcel.2008.04.009

Kamalathevan, P., Zhu, L., Vincent, T. L., and Furniss, D. (2021). Restoring Redox Balance in Cartilage Following Injury Restores Retinoic Acid Levels and Prevents Mechanoflammation. Osteoarthritis and Cartilage 29, S36-S37. doi:10.1016/j.joca.2021.02.056

Karachalios, T., Paridis, D., Tekos, F., Skaperda, Z., Veskoukis, A. S., and Kouretas, D. (2021). Patients Undergoing Surgery for Hip Fractures Suffer from Severe Oxidative Stress as Compared to Patients with Hip Osteoarthritis Undergoing Total Hip Arthroplasty. Oxid. Med. Cel. Longev. 2021. 1-10. doi:10.1155/2021/5542634

Kaur, H., Siraki, A. G., Uludağ, H., Dederich, D. N., Flood, P., and El-Bialy, T. (2017). Role of Reactive Oxygen Species during Low-Intensity Pulsed Ultrasound Application in MC-3 T3 E1 Pre-osteoblast Cell Culture. Ultrasound Med. Biol. 43, 2699-2712. doi:10.1016/j.ultrasmedbio.2017.07.002

Kim, D., and Park, Y. (2021). Dietary Total Antioxidant Capacity Was Associated with Bone Mass and the Risk of Osteoporosis in Postmenopausal Women. Curr. Dev. Nutr. 5, 28. doi:10.1093/cdn/nzab033_028

Kim, H.-N., Ponte, F., Warren, A., Ring, R., Iyer, S., Han, L., et al. (2021). A Decrease in NAD+ Contributes to the Loss of Osteoprogenitors and Bone Mass with Aging. NPJ Aging Mech. Dis. 7, 8. doi:10.1038/s41514-021-00058-7

Kitamoto, K., Miura, Y., Karnan, S., Ota, A., Konishi, H., Hosokawa, Y., et al. (2018). Inhibition of NADPH Oxidase 2 Induces Apoptosis in Osteosarcoma: The Role of Reactive Oxygen Species in Cell Proliferation. Oncol. Lett. 15, 7955-7962. doi:10.3892/ol.2018.8291

Klatt, P., Molina, E. P., and Lamas, S. (1999). Nitric Oxide Inhibits C-Jun DNA Binding by Specifically TargetedS-Glutathionylation. J. Biol. Chem. 274, 15857-15864. doi:10.1074/jbc.274.22.15857

Klotz, L.-O., Sánchez-Ramos, C., Prieto-Arroyo, I., Urbánek, P., Steinbrenner, H., and Monsalve, M. (2015). Redox Regulation of FoxO Transcription Factors. Redox Biol. 6, 51-72. doi:10.1016/j.redox.2015.06.019

Kohli, N., Stoddart, J. C., and van Arkel, R. J. (2021). The Limit of Tolerable Micromotion for Implant Osseointegration: a Systematic Review. Sci. Rep. 11, 10797. doi:10.1038/s41598-021-90142-5

Korac, B., Kalezic, A., Pekovic-Vaughan, V., Korac, A., and Jankovic, A. (2021). Redox Changes in Obesity, Metabolic Syndrome, and Diabetes. Redox Biol. 42, 101887. doi:10.1016/j.redox.2021.101887

Le Rossignol, S., Ketheesan, N., and Haleagrahara, N. (2018). Redox-sensitive Transcription Factors Play a Significant Role in the Development of Rheumatoid Arthritis. Int. Rev. Immunol. 37, 129-143. doi:10.1080/08830185.2017.1363198

Lean, J. M., Jagger, C. J., Kirstein, B., Fuller, K., and Chambers, T. J. (2005). Hydrogen Peroxide Is Essential for Estrogen-Deficiency Bone Loss and Osteoclast Formation. Endocrinology 146, 728-735. doi:10.1210/en.2004-1021

Lepetsos, P., Papavassiliou, K. A., and Papavassiliou, A. G. (2019). Redox and NFKb Signaling in Osteoarthritis. Free Radic. Biol. Med. 132, 90-100. doi:10.1016/ j.freeradbiomed.2018.09.025

Li, L., Zhang, C., Chen, J. 1., Hong, F. f., Chen, P., and Wang, J. f. (2019). Effects of Simulated Microgravity on the Expression Profiles of RNA during Osteogenic Differentiation of Human Bone Marrow Mesenchymal Stem Cells. Cell Prolif 52, e12539. doi:10.1111/cpr.12539

Liao, C.-R., Wang, S.-N., Zhu, S.-Y., Wang, Y.-Q., Li, Z.-Z., Liu, Z.-Y., et al. (2020). Advanced Oxidation Protein Products Increase TNF- $\alpha$ and IL- $1 \beta$ Expression in Chondrocytes via NADPH Oxidase 4 and Accelerate Cartilage Degeneration in Osteoarthritis Progression. Redox Biol. 28, 101306. doi:10.1016/j.redox.2019.101306

Liu, Y., Zhu, W., Ni, D., Zhou, Z., Gu, J.-H., Zhang, W., et al. (2020). Alpha Lipoic Acid Antagonizes Cytotoxicity of Cobalt Nanoparticles by Inhibiting Ferroptosis-like Cell Death. J. Nanobiotechnol 18, 141. doi:10.1186/s12951020-00700-8

Loenarz, C., Coleman, M. L., Boleininger, A., Schierwater, B., Holland, P. W. H., Ratcliffe, P. J., et al. (2011). The Hypoxia-inducible Transcription Factor Pathway Regulates Oxygen Sensing in the Simplest Animal, Trichoplax Adhaerens. EMBO Rep. 12, 63-70. doi:10.1038/embor.2010.170

Lu, Y., Sun, Y., Zhu, J., Yu, L., Jiang, X., Zhang, J., et al. (2018). Oridonin Exerts Anticancer Effect on Osteosarcoma by Activating PPAR- $\gamma$ and Inhibiting Nrf2 Pathway. Cel Death Dis 9, 15-16. doi:10.1038/s41419-017-0031-6

Ma, L., Hua, R., Tian, Y., Cheng, H., Fajardo, R. J., Pearson, J. J., et al. (2019). Connexin 43 Hemichannels Protect Bone Loss during Estrogen Deficiency. Bone Res. 7, 11. doi:10.1038/s41413-019-0050-2
Meesters, D. M., Neubert, S., Wijnands, K. A. P., Heyer, F. L., Zeiter, S., Ito, K., et al. (2016). Deficiency of Inducible and Endothelial Nitric Oxide Synthase Results in Diminished Bone Formation and Delayed union and Nonunion Development. Bone 83, 111-118. doi:10.1016/j.bone.2015.11.006

Meza, C. A., La Favor, J. D., Kim, D.-H., and Hickner, R. C. (2019). Endothelial Dysfunction: Is There a Hyperglycemia-Induced Imbalance of NOX and NOS? Ijms 20, 3775. doi:10.3390/ijms20153775

Michaletti, A., Gioia, M., Tarantino, U., and Zolla, L. (2017). Effects of Microgravity on Osteoblast Mitochondria: a Proteomic and Metabolomics Profile. Sci. Rep. 7, 15376. doi:10.1038/s41598-017-15612-1

Miclau, K. R., Brazina, S. A., Bahney, C. S., Hankenson, K. D., Hunt, T. K., Marcucio, R. S., et al. (2017). Stimulating Fracture Healing in Ischemic Environments: Does Oxygen Direct Stem Cell Fate during Fracture Healing? Front. Cel Dev. Biol. 5, 45. doi:10.3389/fcell.2017.00045

Mittal, M., Siddiqui, M. R., Tran, K., Reddy, S. P., and Malik, A. B. (2014). Reactive Oxygen Species in Inflammation and Tissue Injury. Antioxid. Redox Signaling 20, 1126-1167. doi:10.1089/ars.2012.5149

Morikawa, D., Nojiri, H., Saita, Y., Kobayashi, K., Watanabe, K., Ozawa, Y., et al. (2013). Cytoplasmic Reactive Oxygen Species and SOD1 Regulate Bone Mass during Mechanical Unloading. J. Bone Miner. Res. 28, 2368-2380. doi:10.1002/ jbmr.1981

Mouthuy, P.-A., Snelling, S. J. B., Dakin, S. G., Milković, L., Gašparović, A. Č., Carr, A. J., et al. (2016). Biocompatibility of Implantable Materials: An Oxidative Stress Viewpoint. Biomaterials 109, 55-68. doi:10.1016/j.biomaterials.2016.09.010

Muinos-López, E., Ripalda-Cemboráin, P., López-Martínez, T., González-Gil, A. B., Lamo-Espinosa, J. M., Valentí, A., et al. (2016). Hypoxia and Reactive Oxygen Species Homeostasis in Mesenchymal Progenitor Cells Define a Molecular Mechanism for Fracture Nonunion. Stem Cells 34, 2342-2353. doi:10.1002/stem.2399

Mullender, M., El Haj, A. J., Yang, Y., van Duin, M. A., Burger, E. H., and Klein-Nulend, J. (2004). Mechanotransduction of Bone Cellsin Vitro: Mechanobiology of Bone Tissue. Med. Biol. Eng. Comput. 42, 14-21. doi:10.1007/bf02351006

Ohyama, Y., Ito, J., Kitano, V. J., Shimada, J., and Hakeda, Y. (2018). The Polymethoxy Flavonoid Sudachitin Suppresses Inflammatory Bone Destruction by Directly Inhibiting Osteoclastogenesis Due to Reduced ROS Production and MAPK Activation in Osteoclast Precursors. PLoS One 13, e0191192. doi:10.1371/journal.pone.0191192

Ozawa, R., Saita, M., Sakaue, S., Okada, R., Sato, T., Kawamata, R., et al. (2020). Redox Injectable Gel Protects Osteoblastic Function against Oxidative Stress and Suppresses Alveolar Bone Loss in a Rat Peri-Implantitis Model. Acta Biomater. 110, 82-94. doi:10.1016/j.actbio.2020.04.003

Pang, M., Rodríguez-Gonzalez, M., Hernandez, M., Recinos, C. C., Seldeen, K. L., and Troen, B. R. (2019). AP-1 and Mitf Interact with NFATc1 to Stimulate Cathepsin K Promoter Activity in Osteoclast Precursors. J. Cel. Biochem. 120, 12382-12392. doi:10.1002/jcb.28504

Panieri, E., and Saso, L. (2019). Potential Applications of NRF2 Inhibitors in Cancer Therapy. Oxid. Med. Cel. Longev. 2019, 8592348. doi:10.1155/2019/8592348

Park, J.-Y., Kim, Y. W., and Park, Y.-K. (2012). Nrf2 Expression Is Associated with Poor Outcome in Osteosarcoma. Pathology 44, 617-621. doi:10.1097/ pat.0b013e328359d54b

Pereira, E. J., Smolko, C. M., and Janes, K. A. (2016). Computational Models of Reactive Oxygen Species as Metabolic Byproducts and Signal-Transduction Modulators. Front. Pharmacol. 7, 457. doi:10.3389/fphar.2016.00457

Psefteli, P.-M., Kitscha, P., Vizcay, G., Fleck, R., Chapple, S. J., Mann, G. E., et al. (2021). Glycocalyx Sialic Acids Regulate Nrf2-Mediated Signaling by Fluid Shear Stress in Human Endothelial Cells. Redox Biol. 38, 101816. doi:10.1016/ j.redox.2020.101816

Rahimi, E., Offoiach, R., Hosseinpour, S., Davoodi, A., Baert, K., Lutz, A., et al. (2021). Effect of Hydrogen Peroxide on Bovine Serum Albumin Adsorption on Ti6Al4V alloy: A Scanning Kelvin Probe Force Microscopy Study. Appl. Surf. Sci. 563, 150364. doi:10.1016/j.apsusc.2021.150364

Ramos, A., Duarte, R. J., and Mesnard, M. (2015). Prediction at Long-Term Condyle Screw Fixation of Temporomandibular Joint Implant: A Numerical Study. J. Craniomaxillofac. Surg. 43, 469-474. doi:10.1016/j.jcms.2015.02.013

Ramos, A., Duarte, R. J., Relvas, C., Completo, A., and Simões, J. A. (2013). The Influence of Acetabular Bone Cracks in the Press-Fit Hip Replacement: Numerical and Experimental Analysis. Clin. Biomech. 28, 635-641. doi:10.1016/j.clinbiomech.2013.06.005 
Roberts, W. E., Huja, S., and Roberts, J. A. (2004). Bone Modeling: Biomechanics, Molecular Mechanisms, and Clinical Perspectives. Semin. Orthod. 10, 123-161. doi:10.1053/j.sodo.2004.01.003

Rosenfeldt, F., Wilson, M., Lee, G., Kure, C., Ou, R., Braun, L., et al. (2013). Oxidative Stress in Surgery in an Ageing Population: Pathophysiology and Therapy. Exp. Gerontol. 48, 45-54. doi:10.1016/j.exger.2012.03.010

Roux, E., Bougaran, P., Dufourcq, P., and Couffinhal, T. (2020). Fluid Shear Stress Sensing by the Endothelial Layer. Front. Physiol. 11, 861. doi:10.3389/fphys.2020.00861

Rubin, C. T., and Lanyon, L. E. (1984). Regulation of Bone Formation by Applied Dynamic Loads. J. Bone Jt. Surg. 66, 397-402. doi:10.2106/00004623-198466030-00012

Sánchez-de-Diego, C., Pedrazza, L., Pimenta-Lopes, C., Martinez-Martinez, A., Dahdah, N., Valer, J. A., et al. (2021). NRF2 Function in Osteocytes Is Required for Bone Homeostasis and Drives Osteocytic Gene Expression. Redox Biol. 40, 101845. doi:10.1016/j.redox.2020.101845

Schröder, K. (2015). NADPH Oxidases in Bone Homeostasis and Osteoporosis. Cell. Mol. Life Sci. 72, 25-38. doi:10.1007/s00018-014-1712-2

Shao, D., Li, K., Hu, T., Wang, S., Xu, H., Zhang, S., et al. (2021). Titania Nanotube Array Supported Nanoceria with Redox Cycling Stability Ameliorates Oxidative Stress-Inhibited Osteogenesis. Chem. Eng. J. 415, 128913. doi:10.1016/j.cej.2021.128913

Sharma, A., and Flora, S. J. S. (2021). Positive and Negative Regulation of Ferroptosis and its Role in Maintaining Metabolic and Redox Homeostasis. Oxid. Med. Cel. Longev. 2021, 9074206. doi:10.1155/2021/9074206

Shen, X., Wan, C., Ramaswamy, G., Mavalli, M., Wang, Y., Duvall, C. L., et al. (2009). Prolyl Hydroxylase Inhibitors Increase Neoangiogenesis and Callus Formation Following Femur Fracture in Mice. J. Orthop. Res. 27, 1298-1305. doi:10.1002/jor.20886

Sies, H. (2019). Oxidative Stress: Eustress and Distress. Cambridge: Academic Press.

Sies, H., Berndt, C., and Jones, D. P. (2017). Oxidative Stress. Annu. Rev. Biochem. 86, 715-748. doi:10.1146/annurev-biochem-061516-045037

Son, Y., Kim, S., Chung, H.-T., and Pae, H.-O. (2013). Reactive Oxygen Species in the Activation of MAP Kinases. Methods Enzymol. 528, 27-48. doi:10.1016/ b978-0-12-405881-1.00002-1

Song, J., Liu, H., Lei, M., Tan, H., Chen, Z., Antoshin, A., et al. (2020). RedoxChanneling Polydopamine-Ferrocene (PDA-Fc) Coating to Confer Contextdependent and Photothermal Antimicrobial Activities. ACS Appl. Mater. Inter. 12, 8915-8928. doi:10.1021/acsami.9b22339

Sthijns, M. M. J. P. E., van Blitterswijk, C. A., and LaPointe, V. L. S. (2018). Redox Regulation in Regenerative Medicine and Tissue Engineering: The Paradox of Oxygen. J. Tissue Eng. Regen. Med. 12, 2013-2020. doi:10.1002/term.2730

Sthijns, M. M. J. P. E., Jetten, M. J., Mohammed, S. G., Claessen, S. M. H., de Vries, R. H. W., Stell, A., et al. (2021). Oxidative Stress in Pancreatic Alpha and Beta Cells as a Selection Criterion for Biocompatible Biomaterials. Biomaterials 267, 120449. doi:10.1016/j.biomaterials.2020.120449

Sugiyama, T., Kim, Y. T., and Oda, H. (2016). "Skeletal Adaptation to Mechanical Strain: A Key Role in Osteoporosis," in Osteoporosis in Orthopedics: Assessment and Therapeutic Options. Editors Y. Shimada and N. Miyakoshi (Tokyo: Springer Japan), 3-22. doi:10.1007/978-4-431-55778-4_1

Sun, Y.-X., Xu, A.-H., Yang, Y., and Li, J. (2015). Role of Nrf2 in Bone Metabolism. J. Biomed. Sci. 22, 101. doi:10.1186/s12929-015-0212-5

Sundh, D., Nilsson, M., Zoulakis, M., Pasco, C., Yilmaz, M., Kazakia, G. J., et al. (2018). High-Impact Mechanical Loading Increases Bone Material Strength in Postmenopausal Women-A 3-Month Intervention Study. J. Bone Miner Res. 33, 1242-1251. doi:10.1002/jbmr.3431

Telkoparan-Akillilar, P., Panieri, E., Cevik, D., Suzen, S., and Saso, L. (2021). Therapeutic Targeting of the NRF2 Signaling Pathway in Cancer. Molecules 26, 1417. doi:10.3390/molecules 26051417

Uda, Y., Spatz, J. M., Hussein, A., Garcia, J. H., Lai, F., Dedic, C., et al. (2021). Global Transcriptomic Analysis of a Murine Osteocytic Cell Line Subjected to Spaceflight. FASEB J. 35, e21578. doi:10.1096/fj.202100059R

Wagner, E. F. (2010). Bone Development and Inflammatory Disease Is Regulated by AP-1 (Fos/Jun). Ann. Rheum. Dis. 69 (1), i86-i88. doi:10.1136/ard.2009.119396

Walsh, S. K., Skala, M. C., and Henak, C. R. (2019). Real-time Optical Redox Imaging of Cartilage Metabolic Response to Mechanical Loading. Osteoarthritis and Cartilage 27, 1841-1850. doi:10.1016/j.joca.2019.08.004
Wan, C., Shao, J., Gilbert, S. R., Riddle, R. C., Long, F., Johnson, R. S., et al. (2010). Role of HIF-1 $\alpha$ in Skeletal Development. Ann. N. Y. Acad. Sci. 1192, 322-326. doi:10.1111/j.1749-6632.2009.05238.x

Wang, F.-S., Wu, R.-W., Chen, Y.-S., Ko, J.-Y., Jahr, H., and Lian, W.-S. (2021a). Biophysical Modulation of the Mitochondrial Metabolism and Redox in Bone Homeostasis and Osteoporosis: How Biophysics Converts into Bioenergetics. Antioxidants 10, 1394. doi:10.3390/antiox10091394

Wang, G., Xia, J., Chen, C., Qiu, J., Sun, P., Peng, Z., et al. (2020). SLC25A10 Performs an Oncogenic Role in Human Osteosarcoma. Oncol. Lett. 20, 2. doi:10.3892/ol.2020.11863

Wang, Y. N., Jia, T. T., Feng, Y., Liu, S. Y., Zhang, W. J., Zhang, D. J., et al. (2021b). Hyperlipidemia Impairs Osseointegration via the ROS/Wnt/ $\beta$-Catenin Pathway. J. Dent. Res. 100, 658-665. doi:10.1177/ 0022034520983245

Watanuki, M., Sakai, A., Sakata, T., Tsurukami, H., Miwa, M., Uchida, Y., et al. (2002). Role of Inducible Nitric Oxide Synthase in Skeletal Adaptation to Acute Increases in Mechanical Loading. J. Bone Miner. Res. 17, 1015-1025. doi:10.1359/jbmr.2002.17.6.1015

Wauquier, F., Leotoing, L., Coxam, V., Guicheux, J., and Wittrant, Y. (2009). Oxidative Stress in Bone Remodelling and Disease. Trends Mol. Med. 15, 468-477. doi:10.1016/j.molmed.2009.08.004

Wegner, A. M., and Haudenschild, D. R. (2020). NADPH Oxidases in Bone and Cartilage Homeostasis and Disease: A Promising Therapeutic Target. J. Orthop. Res. 38, 2104-2112. doi:10.1002/jor.24693

Wijnands, K. A., Brink, P. R., Weijers, P. H., Dejong, C. H., and Poeze, M. (2012). Impaired Fracture Healing Associated with Amino Acid Disturbances. Am. J. Clin. Nutr. 95, 1270-1277. doi:10.3945/ajcn.110.009209

Xing, W., Singgih, A., Kapoor, A., Alarcon, C. M., Baylink, D. J., and Mohan, S. (2007). Nuclear Factor-E2-Related Factor-1 Mediates Ascorbic Acid Induction of Osterix Expression via Interaction with AntioxidantResponsive Element in Bone Cells. J. Biol. Chem. 282, 22052-22061. doi:10.1074/jbc.m702614200

Yang, F., Wang, J., Cao, L., Chen, R., Tang, L., and Liu, C. (2014). Injectable and Redox-Responsive Hydrogel with Adaptive Degradation Rate for Bone Regeneration. J. Mater. Chem. B 2, 295-304. doi:10.1039/c3tb21103g

Yang, S., Guo, L., Su, Y., Wen, J., Du, J., Li, X., et al. (2018). Nitric Oxide Balances Osteoblast and Adipocyte Lineage Differentiation via the JNK/MAPK Signaling Pathway in Periodontal Ligament Stem Cells. Stem Cel Res. Ther. 9, 118. doi:10.1186/s13287-018-0869-2

Yavropoulou, M. P., and Yovos, J. G. (2016). The Molecular Basis of Bone Mechanotransduction. J. Musculoskelet. Neuronal Interact. 16, 221-236.

Yu, Z., Xiao, Z., Shuai, X., and Tian, J. (2020). Local Delivery of Sunitinib and Ce6 via Redox-Responsive Zwitterionic Hydrogels Effectively Prevents Osteosarcoma Recurrence. J. Mater. Chem. B 8, 6418-6428. doi:10.1039/d0tb00970a

Zhang, Y., Choksi, S., Chen, K., Pobezinskaya, Y., Linnoila, I., and Liu, Z.-G. (2013). ROS Play a Critical Role in the Differentiation of Alternatively Activated Macrophages and the Occurrence of Tumor-Associated Macrophages. Cell Res 23, 898-914. doi:10.1038/cr.2013.75

Conflict of Interest: The authors declare that the research was conducted in the absence of any commercial or financial relationships that could be construed as a potential conflict of interest.

Publisher's Note: All claims expressed in this article are solely those of the authors and do not necessarily represent those of their affiliated organizations, or those of the publisher, the editors and the reviewers. Any product that may be evaluated in this article, or claim that may be made by its manufacturer, is not guaranteed or endorsed by the publisher.

Copyright (c) 2021 Reis and Ramos. This is an open-access article distributed under the terms of the Creative Commons Attribution License (CC BY). The use, distribution or reproduction in other forums is permitted, provided the original author(s) and the copyright owner(s) are credited and that the original publication in this journal is cited, in accordance with accepted academic practice. No use, distribution or reproduction is permitted which does not comply with these terms. 